\title{
Article \\ Variation of High and Low Level Circulation of Meiyu in Jiangsu Province in Recent 30 Years
}

\author{
Ruoxin $\mathrm{Hu}$ and Lijuan Wang *
}

Citation: Hu, R.; Wang, L. Variation of High and Low Level Circulation of Meiyu in Jiangsu Province in Recent 30 Years. Atmosphere 2021, 12, 1258. https://doi.org/10.3390/ atmos12101258

Academic Editor: Zhaoxia Pu

Received: 31 August 2021

Accepted: 23 September 2021

Published: 27 September 2021

Publisher's Note: MDPI stays neutral with regard to jurisdictional claims in published maps and institutional affiliations.

Copyright: (c) 2021 by the authors. Licensee MDPI, Basel, Switzerland. This article is an open access article distributed under the terms and conditions of the Creative Commons Attribution (CC BY) license (https:// creativecommons.org/licenses/by/ $4.0 /)$.
Key Laboratory of Meteorological Disaster, Ministry of Education/Joint International Research Laboratory of Climate and Environment Change/Collaborative Innovation Center on Forecast and Evaluation of Meteorological Disasters, Nanjing University of Information Science and Technology, Nanjing 210044, China; sandy329@126.com * Correspondence: wljfw@163.com

\begin{abstract}
By using the NCEP/NCAR re-analysis data from 1990 to 2019 and the daily precipitation data of CN05.1 gridded observation dataset, the high and low level circulation characteristics and their influence on the onset and precipitation of Meiyu in Jiangsu Province in recent 30 years are studied. Comparing Meiyu in the 2010s with that in the 1990s, it is found that during the 2010s Meiyu was characterized by a late arrival and less precipitation. There were obviously earlier Meiyu years in the 1990s, while no extremely early Meiyu year existed in the 2010s, which was mainly caused by the late northward jump of the upper jet and the ridge line of the western Pacific subtropical high (WPSH hereinafter) in the 2010s. Compared with the 1990s, the 2010s witnessed an eastward position of the South Asia high and a westward position of the subtropical westerly jet during the Meiyu period, which are not conducive to precipitation in the Yangtze-Huaihe region. At the same time, the cold air flowing southward to the Yangtze-Huaihe region was hindered in the 2010s due to the change of blocking in the middle troposphere. In the 2010s, the water vapor transport and the vertical transportation weakened, resulting in the decrease of precipitation in the Yangtze-Huaihe region.
\end{abstract}

Keywords: Meiyu; high and low level circulation characteristics; the western Pacific subtropical high; the South Asia high; the water vapor transport

\section{Introduction}

Each summer, the northward advancement of the East Asian monsoon effects a rainy season of continuous precipitation in the Yangtze-Huaihe region in China, which is called Meiyu. Frequent occurrences of drought and flood disasters can be seen in the YangtzeHuaihe region, and those in June and July are mostly related to the abnormal Meiyu in that year [1,2]. Therefore, Meiyu has always been a great concern of meteorological research, and valuable achievements have been made on it. The onset and precipitation of the Meiyu are controlled by large-scale circulation factors, and the variation of the East Asian summer monsoon results in the change of the Meiyu [3,4]. The South Asia high and the western Pacific subtropical high (WPSH hereinafter) can directly affect Meiyu as well [5,6]. Moreover, Meiyu is related to the synoptic-scale systems, such as the blocking high, which can make a significant impact on the situation of Meiyu [7,8]. The Meiyu is also affected by climate change. Under the background of global warming, less precipitation of the Meiyu has occurred in the Yangtze-Huaihe region $[9,10]$.

It has been widely proven that the circulation characteristics of the Meiyu period can influence the Meiyu process. According to an analysis of the observation data from 1961 to 2011, it has been concluded that Meiyu in the Yangtze-Huaihe region started late and ended early in the 21st century, and the length and intensity of the rain season were reduced [11]. At the beginning of this century, the Meiyu in Jiangsu was not typical and it was difficult to determine the start and end date of the Meiyu [12]. In 2018, the YangtzeHuaihe region had a late Meiyu and less precipitation due to the northerly subtropical 
upper jet in East Asia, the WPSH, the atypical blocking situation in the middle to high latitudes, and the late onset of the summer monsoon [13,14]. Compared with other years, the year 2017 had a stronger East Asian trough, weaker summer monsoon, and stronger WPSH, resulting in a later Meiyu onset, earlier Meiyu ending, and shorter length and less amount of precipitation in the Yangtze-Huaihe region $[15,16]$. In addition, the Meiyu lasted less time in 2015 and 2016 [17,18], and was even absent in 2014 [19]. All these facts indicate that new characteristics have emerged for the Meiyu in recent years.

Since the 1990s, the onset of Meiyu over the Yangtze-Huaihe region has been delayed, the temporal features and precipitation process of the Meiyu have changed, and the circulation background shows characteristics different from the past. Based on the atmospheric reanalysis data and the Meiyu time data, this work analyzes the variation characteristics of Meiyu and the changes of high and low level circulation in Jiangsu in recent 30 years. At the same time, standards of Meiyu in each region are not completely consistent, and the performance of Meiyu in the south and north of the Yangtze-Huaihe region is slightly different. As a result, this work focuses on the Meiyu in Jiangsu Province, and uses the onset data of Jiangsu Province. By comparing the characteristics of Meiyu in the 2010s to those in the 1990s, this work discusses the interdecadal evolution of Meiyu in recent 30 years, and further reveals the variation pattern and mechanism of Meiyu.

\section{Data and Methods}

Data utilized in this work include: (1) the daily precipitation data of CN05.1 gridded observation data from 1990 to 2019 provided by the National Climate Center of China, which is based on the daily observation data of more than 2400 stations nationwide of the National Meteorological Information Center of China, and has a horizontal resolution of $0.25^{\circ} \times 0.25^{\circ}$; (2) atmospheric re-analysis data from 1990 to 2019 provided by the National Center for Environmental Prediction/the National Center for Atmospheric Research (NCEP/NCAR) of the U.S., including potential height, meridional wind, zonal wind, vertical velocity, relative humidity and other factors with a horizontal resolution of $0.25^{\circ} \times 0.25^{\circ}$; (3) time data of the onset and end of the Meiyu in Jiangsu Province from 1961 to 2019, based on the standards for delimiting Meiyu from Jiangsu Meteorological Observatory.

In this work, the position of the ridge line of the WPSH is determined by the $500-\mathrm{hPa}$ potential height field [20]. The zonal wind meets the geostrophic relationship, and the ridge line meets the following relationship:

$$
\left\{\begin{array}{l}
u=-\frac{1}{f} \frac{\partial \phi}{\partial y}=0 \\
\frac{\partial u}{\partial y}>0
\end{array}\right.
$$

where $u$ is the zonal wind, $f$ is the geostrophic parameter, $\phi$ is the potential height, and $y$ is the vector of meridional.

\section{Results}

\subsection{Evolution Characteristics of Meiyu Onset and End Time in Jiangsu Province}

Based on the onset and end dates of Meiyu in Jiangsu Province, the interdecadal variation characteristics of Meiyu in Jiangsu Province have been discussed. According to the 9-year moving average of the Meiyu onset time of Jiangsu Province from 1961 to 2019 (Figure 1), it can be seen that the overall change trend in the 59 years can be divided into two stages. From 1961 to 1987, the Meiyu onset was gradually advanced over time, and then it was delayed since 1988. The decadal average of the Meiyu onset time shows that Meiyu in Jiangsu was continuously delayed since the 1990s. In this process, the onset and precipitation characteristics of Meiyu and the high and low level circulation background changed. As the initial and end stages of the delay process, the 1990s and the 2010s have obvious differences and can indicate the evolution of Meiyu in recent 30 years. Therefore, the two stages of 1990-1991 and 2010-2019 were analyzed. The 2000s, which can be regarded as a transitional period, will not be specifically discussed in this work. 


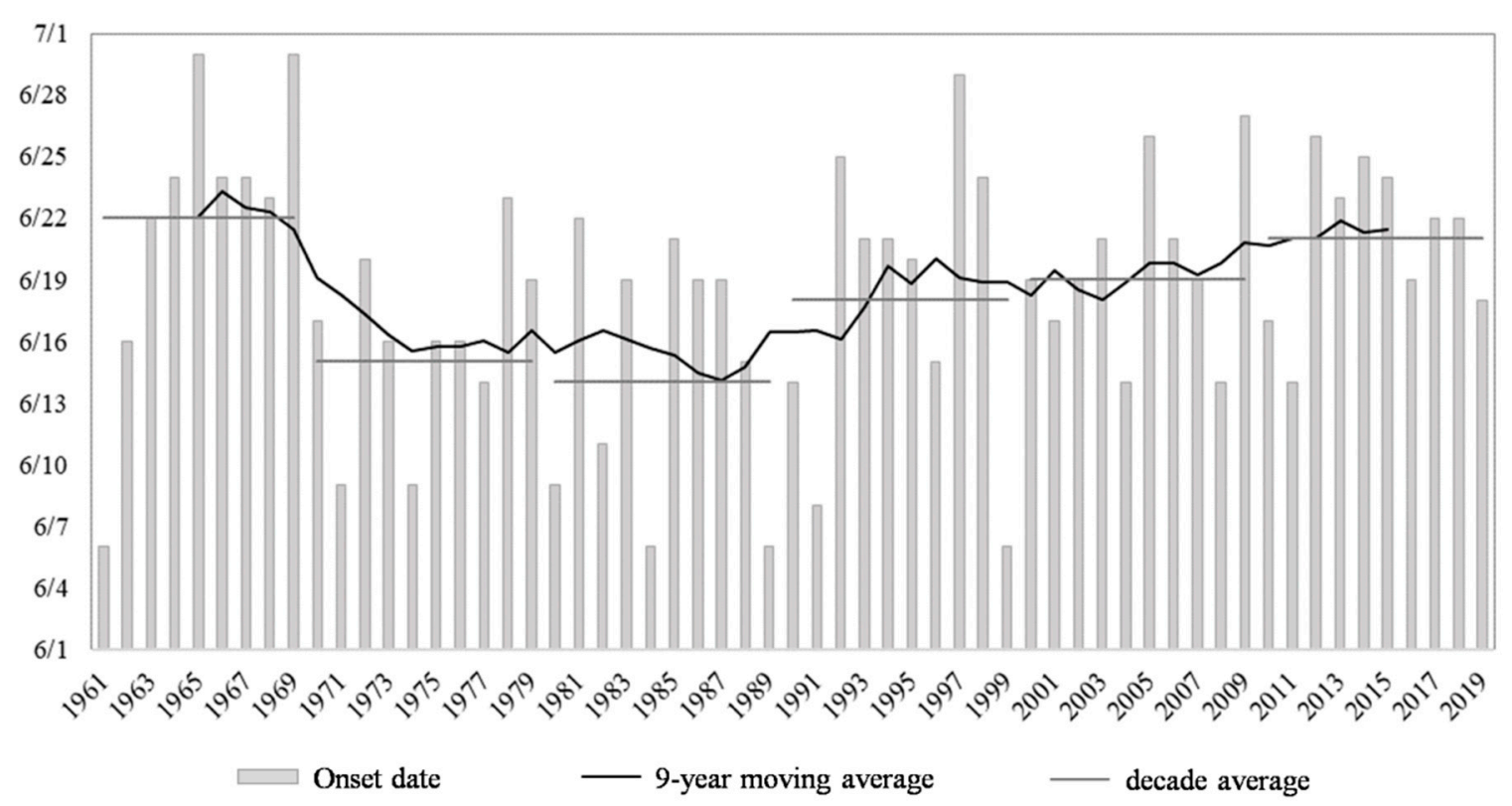

Figure 1. Onset date and interannual and interdecadal sequence of Meiyu in Jiangsu Province from 1961 to 2019.

In order to compare the onset time in the 1990s and 2010s, we standardized the data within each decade respectively, and the standardized sequences of the Meiyu onset time in 1990-1999 (Figure 2a) and 2010-2019 (Figure 2b) were obtained. The positive anomaly standardization means a late onset. In the 1990s, there were great differences in the time of the Meiyu onset in different years. Despite the trend of a delayed Meiyu onset, there were still, though rare, extremely early years in the 59 years. The onsets of Meiyu in the 2010s were more similar than those in the 1990s. Taking 0.6 standard deviations as the indicator, the years whose time of Meiyu onset and length of the Meiyu period exceeding 0.6 positive standard deviations were defined as the early years of the Meiyu onset and the long years of the Meiyu period, respectively. Based on this standard, 1990, 1991 and 1999 were the years with an early arrival of Meiyu in the 1990s, while 1992, 1997 and 1998 were the years with a late arrival of Meiyu in this decade. In the 2010s, 2010, 2011 and 2019 were the years of an early Meiyu arrival, while 2012, 2014 and 2015 witnessed a late arrival. Previous studies have shown that the dates of the Meiyu onset and ending are independent of each other, and there is no significant correlation [2]. Therefore, this work focuses on the difference of abnormal Meiyu onset in different years.
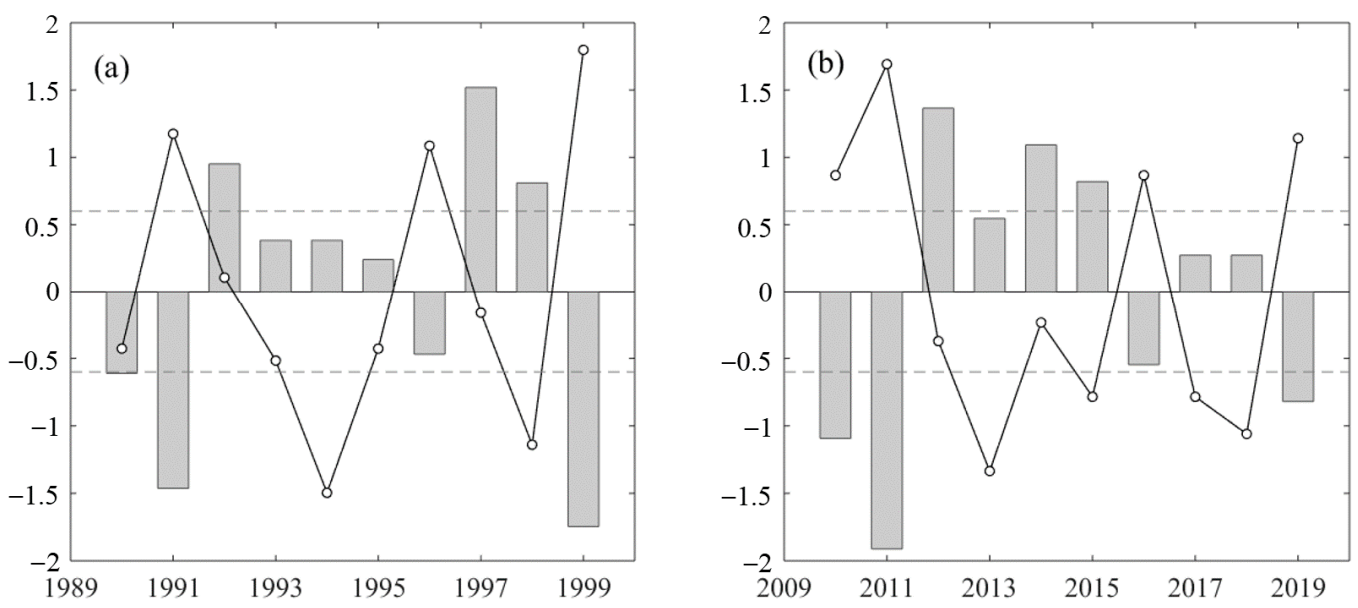

Figure 2. Standardized anomaly of Meiyu onset time from 1990 to 1999 (a) and from 2010 to 2019 (b). 


\subsection{Comparison of Meiyu Characteristics and Rainstorms in 1990-1999 and 2010-2019}

\subsubsection{Meiyu Characteristics}

We took the 12 years selected above as the characteristic cases of the 1990s and the 2010s, respectively, and discussed the variation of Meiyu characteristics with time in recent 30 years. We used the averages of the past 30 years (that is, 1990-2019) as the climatological states of Meiyu to compare with the conditions of the characteristic years. It can be seen from Table 1 that Meiyu with an early arrival in the 1990s had a much earlier onset than that in the climatological state, and the end time was close to the climatological situation. In the second decade, the onset time for Meiyu with an early arrival was only slightly earlier than that in the climatological state, while the time of Meiyu's end was much later. Therefore, the duration of the Meiyu period in both the 1990s and 2010s was much longer than that in the climatological state. For the late-arriving Meiyu, the dates of the Meiyu onset and ending, as well as the duration of Meiyu in the 1990s were similar to those in the second decade. Generally speaking, Meiyu started later in the 2010s than in the 1990s, but there was little difference in how long the Meiyu rain period lasted.

Table 1. Temporal characteristics of Meiyu in 1990s and 2010s.

\begin{tabular}{cccc}
\hline Type & Onset Date & End Date & Days \\
\hline Meiyu with early arrival in the 1990s & 9 June & 13 July & 35 \\
Meiyu with late arrival in the 1990s & 26 June & 15 July & 20 \\
Meiyu with early arrival in the 2010s & 16 June & 20 July & 35 \\
Meiyu with late arrival in the 2010s & 25 June & 16 July & 22 \\
climatological state of Meiyu & 20 June & 12 July & 23 \\
\hline
\end{tabular}

\subsubsection{Rainstorm during Meiyu Period}

Rainstorms often occur during the Meiyu period, and the rainfall intensity and range vary under different circulation backgrounds. According to the ground observation specification of the China Meteorological Administration, a rainstorm is defined when the 24-h precipitation reaches more than $50 \mathrm{~mm}$, and a heavy rainstorm is defined when the precipitation reaches more than $100 \mathrm{~mm}$. Based on this standard, this work conducted statistical analysis on the rainstorm process in Jiangsu Province in the 12 characteristic years. In the grid with a horizontal resolution of $0.25^{\circ}$, when rainstorm precipitation occurred at two consecutive points, it was recorded as a rainstorm process, so as to calculate the days of rainstorms or heavy rainstorms. The days with continuous rainstorm in Jiangsu Province were defined as the rainstorm duration days, and the longest record of duration days over the years was regarded as the longest duration of rainstorm. The occurrence of rainstorms in the above years is shown in Table 2.

Table 2. Comparison of rainstorms in the Meiyu period in Jiangsu Province.

\begin{tabular}{cccccccc}
\hline $\begin{array}{c}\text { Year of Early } \\
\text { Meiyu } \\
\text { Arrival }\end{array}$ & $\begin{array}{c}\text { Rainstorm } \\
\text { Days }\end{array}$ & $\begin{array}{c}\text { Heavy } \\
\text { Rainstorm } \\
\text { Days }\end{array}$ & $\begin{array}{c}\text { Maximum } \\
\text { Rainstorm } \\
\text { Duration Days }\end{array}$ & $\begin{array}{c}\text { Year of Late } \\
\text { Meiyu } \\
\text { Arrival }\end{array}$ & $\begin{array}{c}\text { Rainstorm } \\
\text { Days }\end{array}$ & $\begin{array}{c}\text { Heavy } \\
\text { Rainstorm } \\
\text { Days }\end{array}$ & $\begin{array}{c}\text { Maximum } \\
\text { Rainstorm } \\
\text { Duration Days }\end{array}$ \\
\hline 1990 & 3 & 0 & 1 & 1992 & 1 & 0 & 1 \\
1991 & 17 & 8 & 5 & 1997 & 4 & 2 & 2 \\
1999 & 14 & 3 & 6 & 1998 & 6 & 0 & 2 \\
2010 & 6 & 1 & 4 & 2012 & 9 & 0 & 1 \\
2011 & 10 & 2 & 4 & 2014 & 4 & 5 & 2 \\
2019 & 5 & 0 & 1 & 2015 & 5 & & 1 \\
\hline
\end{tabular}

In general, Meiyu with an early arrival had stronger and more precipitation processes, and longer duration days of rainstorm than the late-arriving ones. Meanwhile, it was easier to induce heavy rainstorms in the early-arriving Meiyu. Such a phenomenon was more obvious in the 1990s. During this decade, the rainstorm cases for Meiyu with early and late 
onsets were significantly different. Early-arriving Meiyu had much more rainstorms and heavy rainstorm days than a late one, and the rainstorm cases lasted longer. In contrast, although there were more rainstorm days in the early-arriving Meiyu periods than in the late ones for the 2010s, the difference was not clear. A relatively significant feature is that the rainstorm duration days in the early cases were generally longer than those in the late ones. The difference of precipitation characteristics in different years was consistent with the difference of the Meiyu onset time. There was a large discrepancy in the Meiyu onset time between the years of the early-arriving and the late-arriving Meiyu in the 1990s, and the number of rainstorm days also varied to a great extent. Particularly, rainstorms occurred frequently in 1991 and 1999. But the 2010s had little difference in rainstorm days between different Meiyu years, while the deviation of the Meiyu onset time was not as much as that in the 1990s, either.

Moreover, looking into the years within the same category, it can be found that the early Meiyu years were more dissimilar between the 1990s and 2010s than the late Meiyu years. For the early-arriving Meiyu years, more rainstorm days, heavy rainstorm days and continuous duration days existed in the 1990s than in the 2010s. On the whole, during the 1990s the rainstorm process in the Meiyu period occurred more frequently, and there was a noteworthy difference between the years of early and late Meiyu arrival.

\subsection{Effects of Circulation Variation on Meiyu Onset and Precipitation in 1990-1999 and 2010-2019}

\subsubsection{South Asia High and Upper-Level Jet}

As the strongest and most stable atmospheric circulation system in the upper troposphere of the northern hemisphere in summer, the South Asia high (SAH hereinafter) has a vital impact on summer precipitation in China [21]. Its strength, east-west position and north-south shift are closely linked to the onset and end of Meiyu, and also affects the summer rainfall in the Yangtze-Huaihe region of China. Figure 3 shows the locations of the SAH and the upper-level jet during the Meiyu period in the years with the early and late arrival of Meiyu in the 1990s and 2010s. The height of 16,800 gpm at $100 \mathrm{hPa}$ was taken as the characteristic line of the SAH, and the area with a wind speed over $30 \mathrm{~m} / \mathrm{s}$ at $200 \mathrm{hPa}$ was considered the upper-level jet region. It can be seen from the figure that in the 2010s the location of the SAH in the years of the early and late Meiyu arrival was relatively similar, and the range was obviously larger than that in the 1990s. The easternmost point of the SAH exceeded $110^{\circ} \mathrm{E}$ in the 2010s, and the intensity was strong (Figure 3c,d). The location of the SAH in the Meiyu period of the 1990s was slightly westward compared to that in the 2010s, and the range was marginally smaller. The location of the SAH during the years of the late Meiyu arrival in the 1990s was more westward, as its easternmost point was west of $100^{\circ} \mathrm{E}$ (Figure 3a,b). The SAH extending to the east of $110^{\circ} \mathrm{E}$ often causes delay of the Meiyu onset [22]. Furthermore, the SAH located further east in June makes it difficult for the rain belt to move northward, and the SAH further east in July leads to the westerly and northerly extension of the WPSH, which is not conducive to precipitation in the Yangtze-Huaihe region [23]. Therefore, the further east location of the SAH is one of the reasons for the later onset and decreased precipitation in the 2010s than in the 1990s.

With the formation of the $\mathrm{SAH}$, the anticyclone circulation strengthens the pressure gradient on the north side, and the subtropical westerly jet in its north enhances [7]. Due to the geostrophic relation, the strength and location of the SAH have a decisive impact on the westerly jet [24]. Taking $120^{\circ} \mathrm{E}$ as the boundary, the East Asian continental jet and the Western Pacific jet have been proposed according to the location of the upper-level jet axis. The Western Pacific jet plays a significant role in the Meiyu precipitation process in the Yangtze-Huaihe region, as this region is located on the right side of the upper-level jet inlet [25]. The comparison of different decades shows that there was a stable upper-level jet in East Asia in the years with an early Meiyu arrival during the 1990s. The jet had a wide range from east to west, and the Yangtze-Huaihe region was located on the right side of the inlet of the upper-level jet area (Figure 3a). In the years of the late Meiyu arrival during the same decade, the position of the upper-level jet was extremely westward, and the absence 
of the upper-level jet hindered the occurrence of the rainstorm process (Figure 3b). In the 2010s, the location and intensity of the jet over East Asia were relatively similar between the years of the early and late Meiyu arrival. The upper-level jet was the East Asian continental jet, and the convergence on the right side of the jet stream outlet was not conducive to convection and rainstorms (Figure 3c,d).
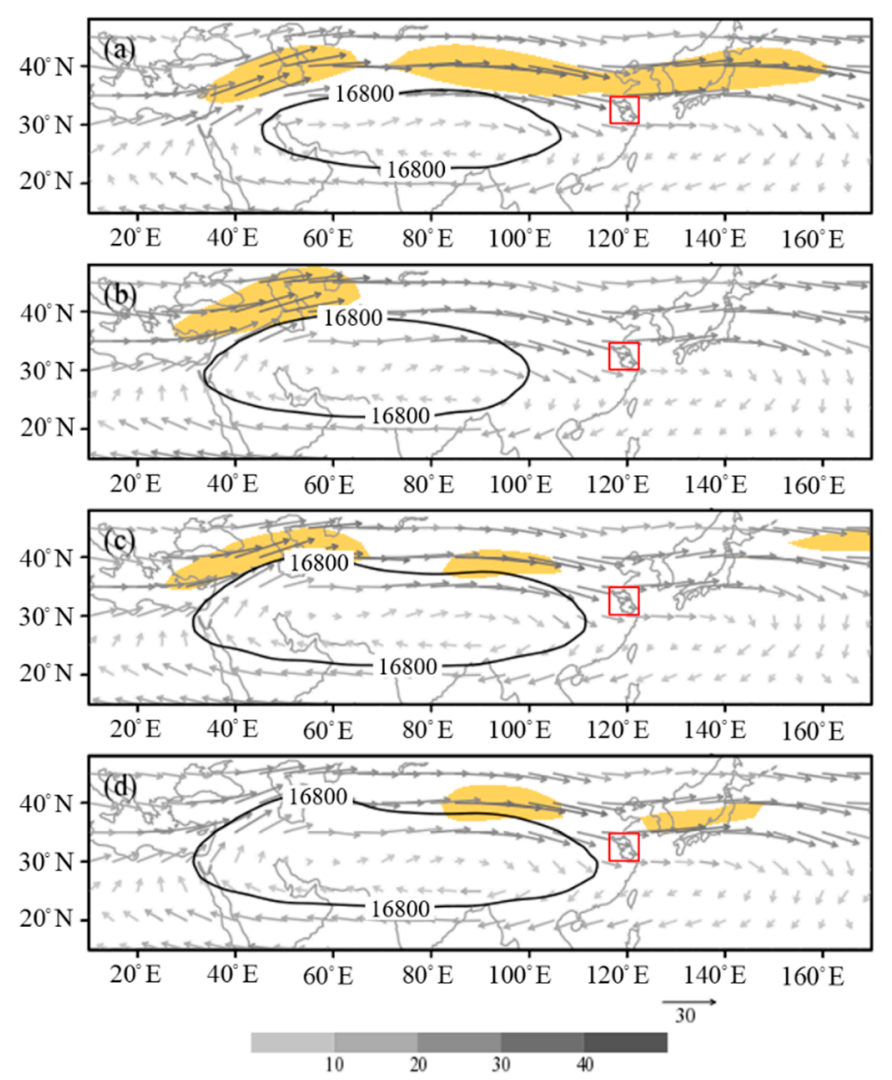

Figure 3. The South Asia high at $100 \mathrm{hPa}$ (the solid line denotes the 16,800-gpm characteristic line), the wind fields at $200 \mathrm{hPa}$ (vector, unit: $\mathrm{m} \cdot \mathrm{s}^{-1}$, the yellow shaded areas denote speed exceeding $30 \mathrm{~m} \cdot \mathrm{s}^{-1}$ ) and the study region (marked in red) of years of early Meiyu arrival in the 1990s (a), late Meiyu arrival in the 1990s (b), early Meiyu arrival in the 2010s (c), and late Meiyu arrival in the 2010s (d).

The north-south position of the upper-level jet before the Meiyu onset and the time of upper-level jet formation are related to the time of the Meiyu onset. As shown in Figure 4, the zonal average of the $200-\mathrm{hPa}$ zonal wind at $110^{\circ} \mathrm{E}$ to $130^{\circ} \mathrm{E}$ was used to indicate the intensity of the upper-level jet affecting the Yangtze-Huaihe region, which can reflect the variation of the position and intensity of the upper-level jet for Meiyu of early arrival and late arrival in the two different decades. Combined with the average time of the Meiyu onset, it can be found that the periods with strong jet flow were mostly before the Meiyu onset. There was still a period of strong jet flow after the Meiyu's start in an early Meiyu arrival year in the $1990 \mathrm{~s}$, while the jet flow in the range of $110^{\circ} \mathrm{E}$ to $130^{\circ} \mathrm{E}$ in the other three types of years was weak in the Meiyu period. Comparing different Meiyu years in the 1990s, the jet axis in the early Meiyu arrival years was basically located at $40^{\circ} \mathrm{N}$, which was much more north than that in the late years; the wind speed was higher, and the duration was longer than that in the late years (Figure $4 a, b$ ). As pointed out by research, the northerly upper-level jet often corresponds to a stronger East Asian summer monsoon system, and its early northward movement results in the early onset of Meiyu in the Yangtze-Huaihe region [26]. However, an almost opposite phenomenon occurred in the 2010s. The jet intensity in the years of an early Meiyu arrival was weaker, the duration was obviously shorter, and the north-south position deviation was not significant (Figure 4c,d). 

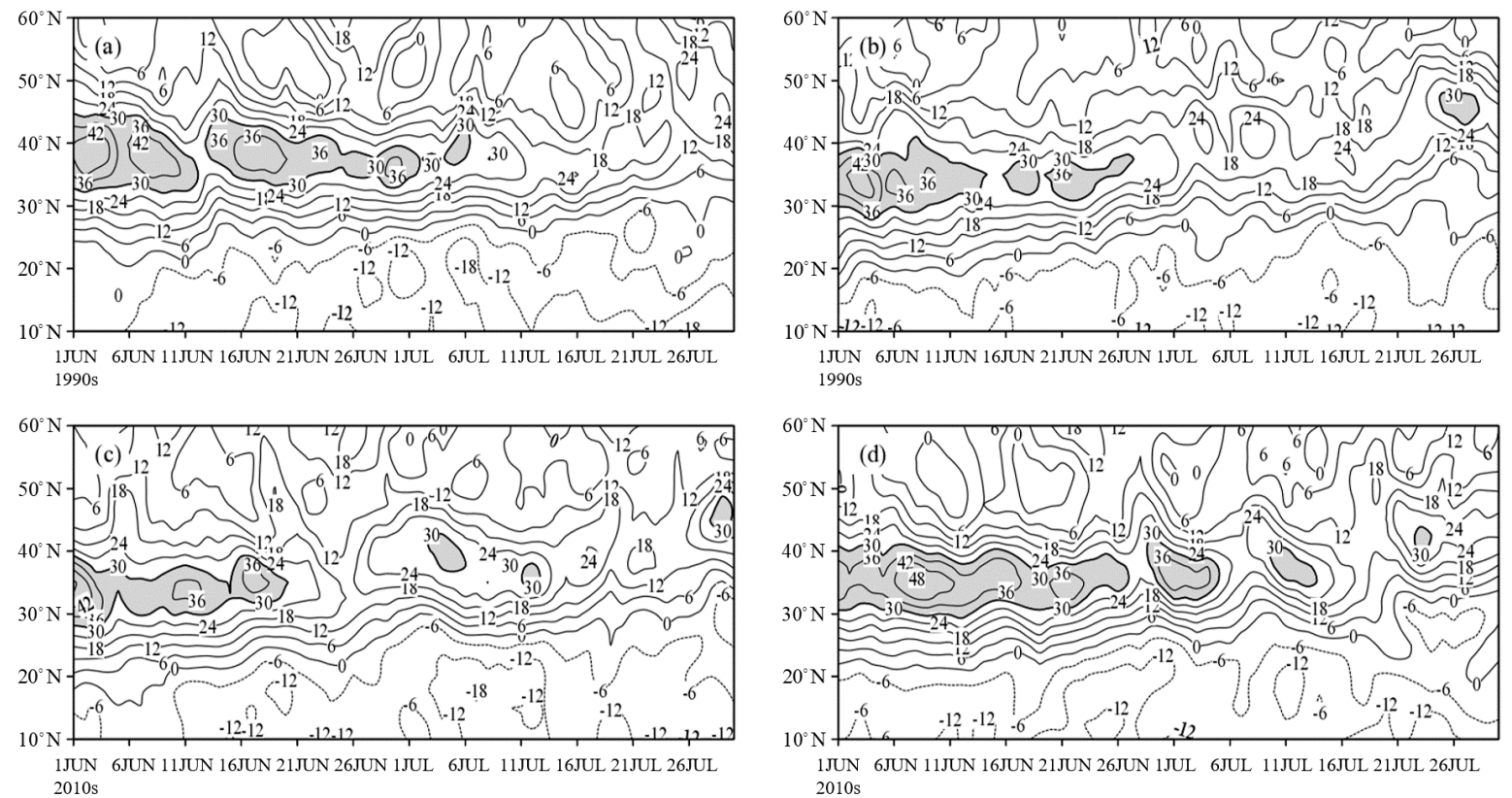

Figure 4. Time-latitude profile along the mean $110 \sim 130^{\circ} \mathrm{E}$ of $200-\mathrm{hPa}$ mean zonal wind from June to July (the solid line denotes wind speed, unit: $\mathrm{m} \cdot \mathrm{s}^{-1}$; the shaded areas denotes wind speed exceeding $30 \mathrm{~m} \cdot \mathrm{s}^{-1}$ ) of years of early Meiyu arrival in the 1990s (a), late Meiyu arrival in the 1990s (b), early Meiyu arrival in the 2010s (c), and late Meiyu arrival in the 2010s (d).

\subsubsection{Western Pacific Subtropical High and Blocking High}

The Western Pacific subtropical high (WPSH hereinafter) is a warm anticyclone system, and its location and intensity are closely related to Meiyu. The northward jump of the WPSH ridgeline plays a critical role in the Meiyu's onset and end, and the westward extension position, north-south oscillation and range of the WPSH have an important impact on the rainfall area and intensity of Meiyu's precipitation.

The latitude of the WSPH ridgeline over $120^{\circ} \mathrm{E}$ at $500 \mathrm{hPa}$ is one of the conditions of the Meiyu onset according to Jiangsu Meteorological Observatory. It stipulates that the ridgeline should be north than $20^{\circ} \mathrm{N}$. Therefore, the discussion on the Jiangsu Meiyu onset needs to consider the location of the WPSH and the moving of the ridgeline. Figure 5 compares the range and ridgeline of 500-hPa WPSH before and after the Meiyu onset in the 1990s and 2010s, and takes the average potential height of $110 \sim 130^{\circ} \mathrm{E}$ as an indication to reflect the north-south shift of the WPSH. In the years of the early Meiyu arrival in the 1990s, the range of the WPSH was small, but the ridgeline of the anticyclone system jumped northward earlier and moved to the north of $20^{\circ} \mathrm{N}$ in the first pentad of June. Although there were short-term fluctuations, the ridgeline basically remained between 20 and $25^{\circ} \mathrm{N}$ until mid-July. The early northward jump of the WPSH and the early formation of the Meiyu circulation system resulted in the early onset of Meiyu in these years (Figure 5a). In contrast, in the years of the late arrival of Meiyu in the 1990s, the WPSH moved northward much later as it propagated to $20^{\circ} \mathrm{N}$ in the fifth pentad of June. It moved slowly and stably before the onset, rather than jumping northward rapidly like the case of the early-arriving Meiyu. The WPSH stayed in the south for a long time, which determined the late start of Meiyu in these years (Figure 5b). In the 2010s, the WPSH appeared early in East Asia in the years of the early Meiyu arrival, but its ridgeline was still in a southerly position for some time until a northward shift occurred at the fourth pentad. Therefore, the onset time for the early-arriving Meiyu of the 2010s was later than that of the 1990s (Figure 5c). The WPSH was formed late in the years of the late Meiyu arrival of the 2010s. The ridgeline of the anticyclone system was at the north of $20^{\circ} \mathrm{N}$ in the first pentad of June, but it remained north for only a few days and then retreated southward. It moved north at the fourth 
pentad, which was close to the condition of the early Meiyu years of the 2010s. However, although the ridgeline completed the north jump, the clear WPSH characteristic line did not appear until the fifth pentad of June. It means that the high pressure zone did not reach the strength of the WPSH until the end of June (Figure 5d). Zhou have pointed out that for the Meiyu with a late arrival, the ridgeline of the WPSH may push northward quickly in late May, but retreats southward due to instability [27], which is similar to this situation in the years of the late Meiyu arrival in the 2010s.
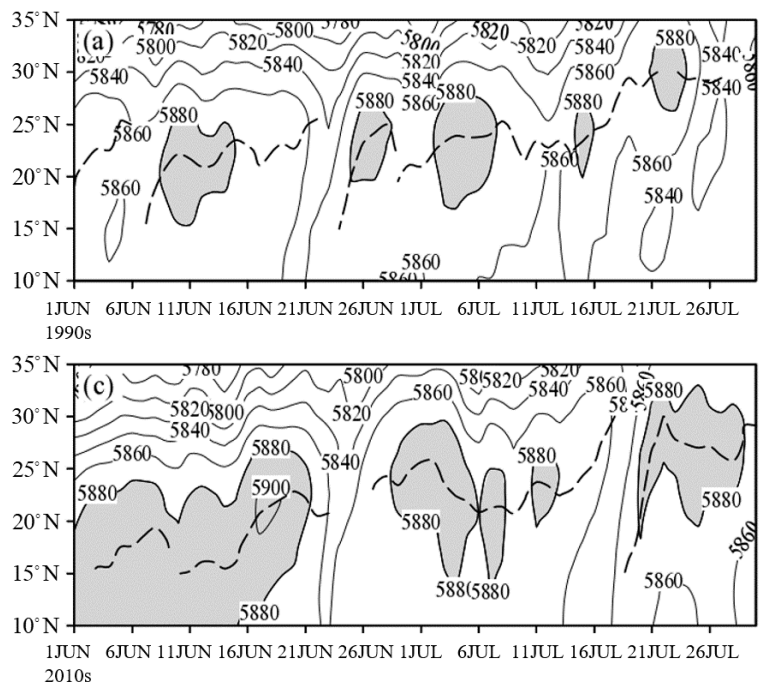
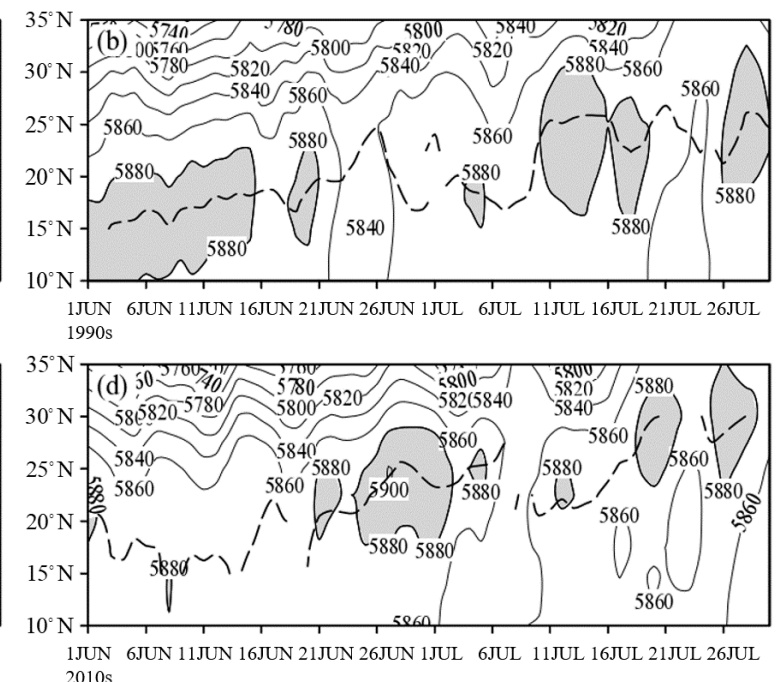

2010 s

Figure 5. Time-latitude profile of 500-hPa mean geopotential height at $110 \sim 130^{\circ} \mathrm{E}$ (the solid line denotes geopotential height, unit: gpm; the shaded areas denotes geopotential height exceeding $5880 \mathrm{gpm}$ ) and western Pacific subtropical high ridgeline (dashed line) from June to July of early-arriving Meiyu in the 1990s (a), late-arriving Meiyu in the 1990s (b), early-arriving Meiyu in the 2010s (c), and late-arriving Meiyu in the 2010s (d).

In the middle troposphere, the blocking situation in the middle and high latitudes can also affect Meiyu. In previous studies, the blocking high in the region of $111 \sim 150^{\circ} \mathrm{E}$ is generally regarded as the east-blocking type, that in the region of $81 \sim 110^{\circ} \mathrm{E}$ the Baikalblocking type, and that in $51 \sim 80^{\circ} \mathrm{E}$ the west-blocking type [28]. The east-blocking high among them, which is stable and less variable, makes more contribution in the years with longer Meiyu periods and has a closer relationship with Meiyu [5]. As can be seen from Figure 6, the blocking situation in the years of the early Meiyu arrival was relatively similar in the 1990s and 2010s, but the blocking situation in the years of the late Meiyu arrival was not typical. For the early-arriving Meiyu in the 1990s, the distribution of blocking high approximated the double-blocking type. Compared with the climatological state, the two high pressures were stronger, and the blocking high was the east-blocking type (Figure 6a). This type of blocking situation can make the cold air invade southward and strengthen the Meiyu front, increase the Meiyu rainstorm, and prolong the Meiyu period by blocking the northward rise of the WPSH [27]. The blocking high for the early-arriving Meiyu in the 2010s was the Baikal-blocking type, which had less effect on cold air transport and Meiyu front maintenance than the east-blocking type (Figure 6c). In contrast, the blocking high of the years with the late Meiyu arrival was weaker. The single-blocking type was shown in the 1990s (Figure 6b), and the blocking situation for the late-arriving Meiyu in the 2010s was not obvious. The westerly belt over middle and high latitudes was relatively flat to the east of the Ural region (Figure 6d). The two kinds of circulation situations can both cause the weak activity of cold air, which is unfavorable to the emergence and maintenance of the Meiyu structure. 

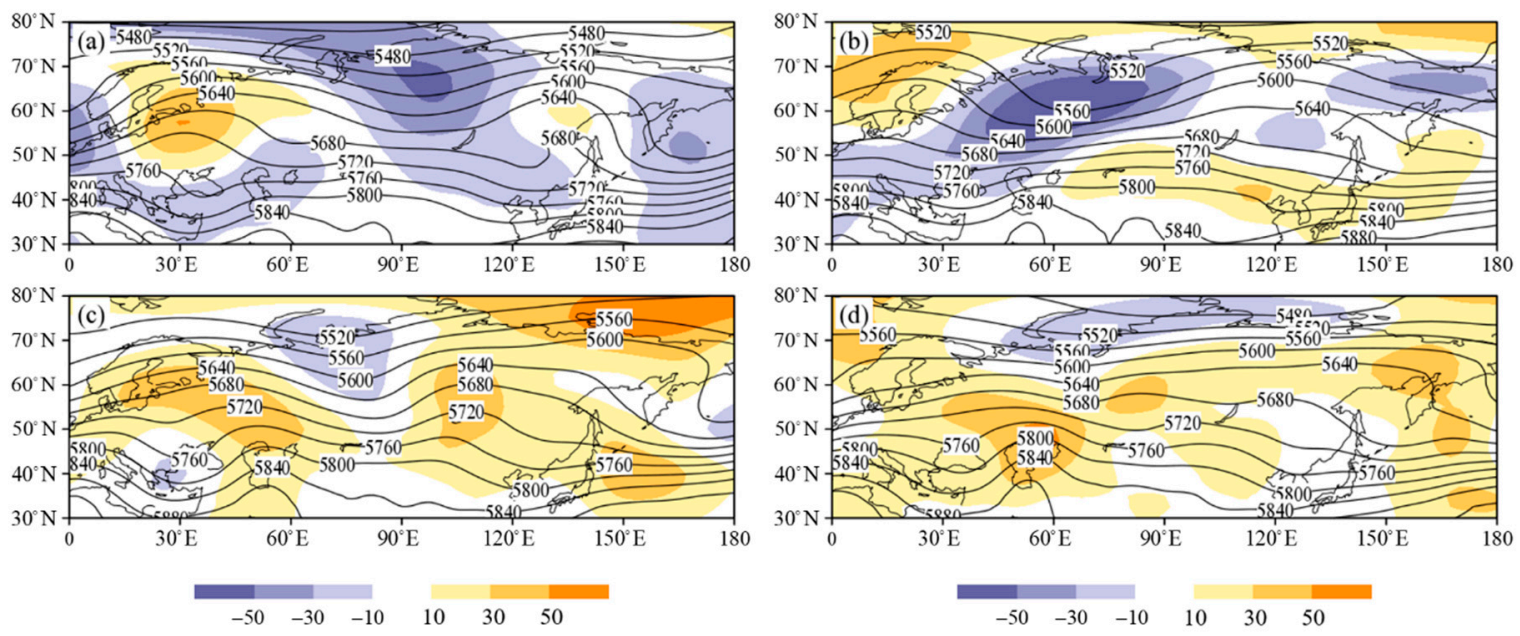

Figure 6. The geopotential height fields at $500 \mathrm{hPa}$ (solid line, units: gpm) and anomaly field compared with climatological state (shaded, units: gpm) of early-arriving Meiyu in the 1990s (a), late-arriving Meiyu in the 1990s (b), early-arriving Meiyu in the 2010s (c), and late-arriving Meiyu in the 2010s (d).

\subsection{Effects of the Variation of Mesoscale Characteristic Factors on Meiyu Precipitation in 1990-1999 and 2010-2019}

\subsubsection{Water Vapor Transport}

Water vapor transport is one of the key factors in precipitation, and the transport of water vapor by the monsoon circulation system in the lower troposphere has an important impact on the rainfall in the Meiyu period. The average water vapor flux and water vapor flux divergence of $850 \mathrm{hPa}$ were analyzed with composites of the Meiyu periods in the 1990s and 2010s. The results are shown in Figure 7. In the 1990s, the air flow from the South China Sea was more southerly. Apart from the southwest air flow in the northern Indian Ocean, a stream of water vapor was also transported northward to the Yangtze-Huaihe region through the South China Sea, and both were transport routes with strong water vapor flux (Figure 7a). The water vapor flux in the 2010s mainly had a southwest direction. The high value area of the water vapor flux shows that a large amount of water vapor was directly transported from the northern Indian Ocean to the Yangtze-Huaihe region, while the water vapor flux transported from south to north near the South China Sea was not as strong as that in the 1990s (Figure 7b). In addition, comparison of the water vapor flux divergence suggests that the convergence in the Yangtze-Huaihe region in the 2010s was weaker than that in the 1990s, which hindered the rainfall there.
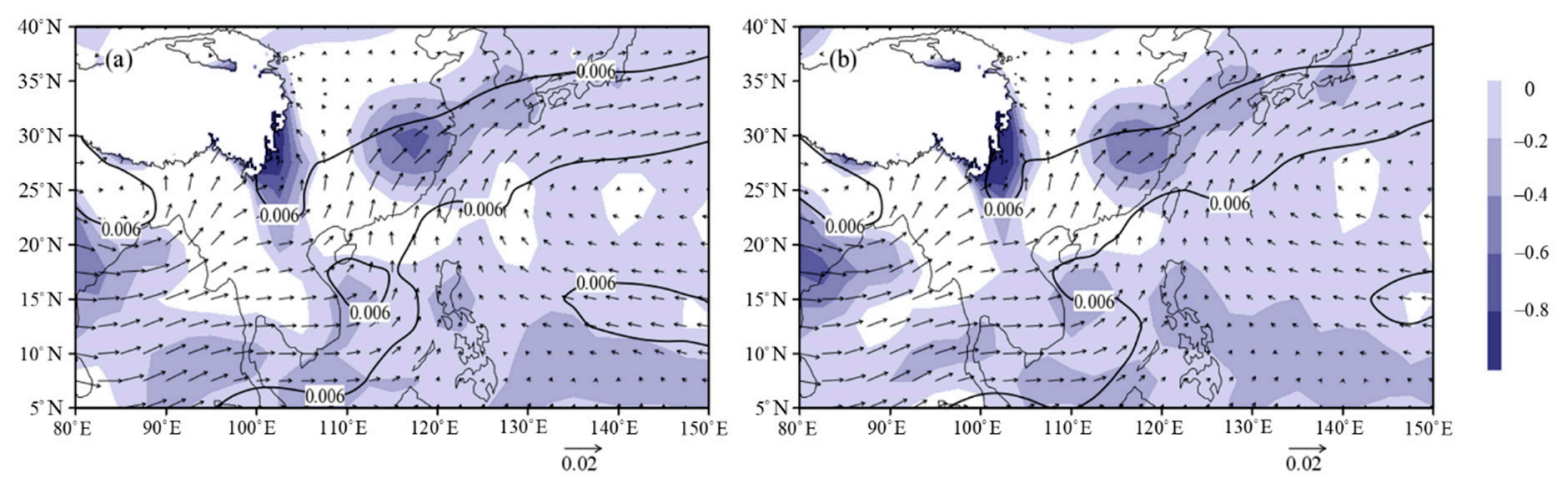

Figure 7. Water vapor flux field at $850 \mathrm{hPa}$ (vector, unit: $\mathrm{s}^{-1}$, the solid line denotes $0.006 \mathrm{~s}^{-1}$ line) and its divergence field (shaded, unit: $10^{-8} \mathrm{~g} /\left(\mathrm{s} \cdot \mathrm{cm}^{2} \cdot \mathrm{hPa}\right)$ ) of Meiyu in the 1990s (a) and 2010s (b).

The Yangtze-Huaihe region is in the southeast of Asia, and its precipitation during the Meiyu period is affected by air masses from several different sources. The three 
sources that contribute most to the water vapor transport in the region are the Indian Ocean, the Western Pacific, and the South China Sea [29]. Different water vapor channels and air mass types can have distinct effects on Meiyu precipitation, and this work takes the intensity of the three water vapor transport channels as a standard to compare the water vapor contribution in different decades. Based on the average distribution of the vertical integration of water vapor flux from 1990 to 2019, we recognized three extreme regions of the vector modes as the water vapor transport channels. It was obtained that the southwest channel's range was $\left(85 \sim 100^{\circ} \mathrm{E}, 15 \sim 22.5^{\circ} \mathrm{N}\right)$, the South China Sea channel's range was $\left(107.5 \sim 117.5^{\circ} \mathrm{E}, 10 \sim 20^{\circ} \mathrm{N}\right)$, and the southeast channel's range was $\left(135 \sim 150^{\circ} \mathrm{E}\right.$, $10 \sim 17.5^{\circ} \mathrm{N}$ ) [30]. The intensities of the three channels are shown in Table 3. The average intensity of the three channels in the 1990s was stronger than that in the 2010s, which proves that the water vapor transmission from the three sources to the Yangtze-Huaihe region in the 1990s was stronger. Furthermore, the intensity of the southwest channel and the South China Sea channel increased synchronously in the early-arriving Meiyu years of the 1990s. The years with abnormal precipitation in Meiyu always have significantly higher water vapor transport from the South China Sea than other years [29], which can explain the strong Meiyu precipitation in the early Meiyu arrival years during the 1990s. As revealed by the contrast of water vapor transport between the 1990s and 2010s, stronger water vapor channels and better water vapor income in the Yangtze-Huaihe region were the reasons for more precipitation in the 1990s. The insufficient water vapor acquisition and the transformation from a south water vapor transport channel to a southwest one caused less precipitation in the 2010s.

Table 3. Intensity index of water vapor channel in Meiyu period (unit: $\mathrm{kg} \cdot \mathrm{m}^{-1} \cdot \mathrm{s}^{-1}$ ).

\begin{tabular}{|c|c|c|c|c|c|c|}
\hline Water Vapor Channels & $\begin{array}{l}\text { Early-Arriving } \\
\text { Meiyu in the } \\
\text { 1990s }\end{array}$ & $\begin{array}{l}\text { Late-Arriving } \\
\text { Meiyu in the } \\
\text { 1990s }\end{array}$ & $\begin{array}{c}\text { Average of } \\
\text { the } 1990 \mathrm{~s}\end{array}$ & $\begin{array}{l}\text { Early-Arriving } \\
\text { Meiyu in the } \\
\text { 2010s }\end{array}$ & $\begin{array}{l}\text { Late-Arriving } \\
\text { Meiyu in the } \\
\text { 2010s }\end{array}$ & $\begin{array}{c}\text { Average } \\
\text { of the } \\
2010 s\end{array}$ \\
\hline Southwest channel & 371.14 & 358.43 & 351.06 & 326.42 & 348.21 & 340.11 \\
\hline Southeast channel & 210.35 & 253.94 & 240.34 & 231.74 & 224.22 & 230.48 \\
\hline South China sea channel & 281.56 & 273.42 & 262.28 & 257.59 & 284.65 & 258.64 \\
\hline
\end{tabular}

\subsubsection{Vertical Convection}

The occurrence of strong rainstorms not only needs an abundant water vapor condition, but also requires the cooperation of a strong upward movement. During the Meiyu period, the low-level jet over the Yangtze-Huaihe region not only provides continuous water vapor transport, but also meets with cold air to form the Meiyu front, thus resulting in vertical convection [31,32]. When comparing the vertical movement in the 1990s and 2010s, the region of $116 \sim 122^{\circ} \mathrm{E}$ was used to characterize the average level of Jiangsu Province and its north and south sides. The longitudinal profile of vertical velocity and radial wind field is shown in Figure 8. In the years of the early Meiyu arrival, there was an upward movement in Jiangsu Province and its south side. In the 1990s, the rising area was wider, and the vertical height of the upper boundary of the rising area was higher (Figure 8a). In the 2010s, the downdraft appeared at the upper troposphere in the south of Jiangsu (Figure 8c). In the 1990s and 2010s, the late-arriving Meiyu experienced a subsidence movement near $20^{\circ} \mathrm{N}$ in the south of Jiangsu Province. The subsidence in the 1990s was mainly in the middle and low level of the troposphere (Figure 8b), while in the 2010s, there was a subsidence area penetrating the entire height of the troposphere in the south of Jiangsu Province, which was mainly related to the westward extension of the WPSH and the eastward extension of the SAH (Figure 8d). For the precipitation process, the vertical convection is a necessary condition to trigger it. The large-scale upward movement in the years of the early Meiyu arrival in the 1990s was a major factor causing more rainstorms, while the strong downdraft in the south of Jiangsu in the years of the late Meiyu arrival in the 2010s hindered the occurrence of rainstorms. 

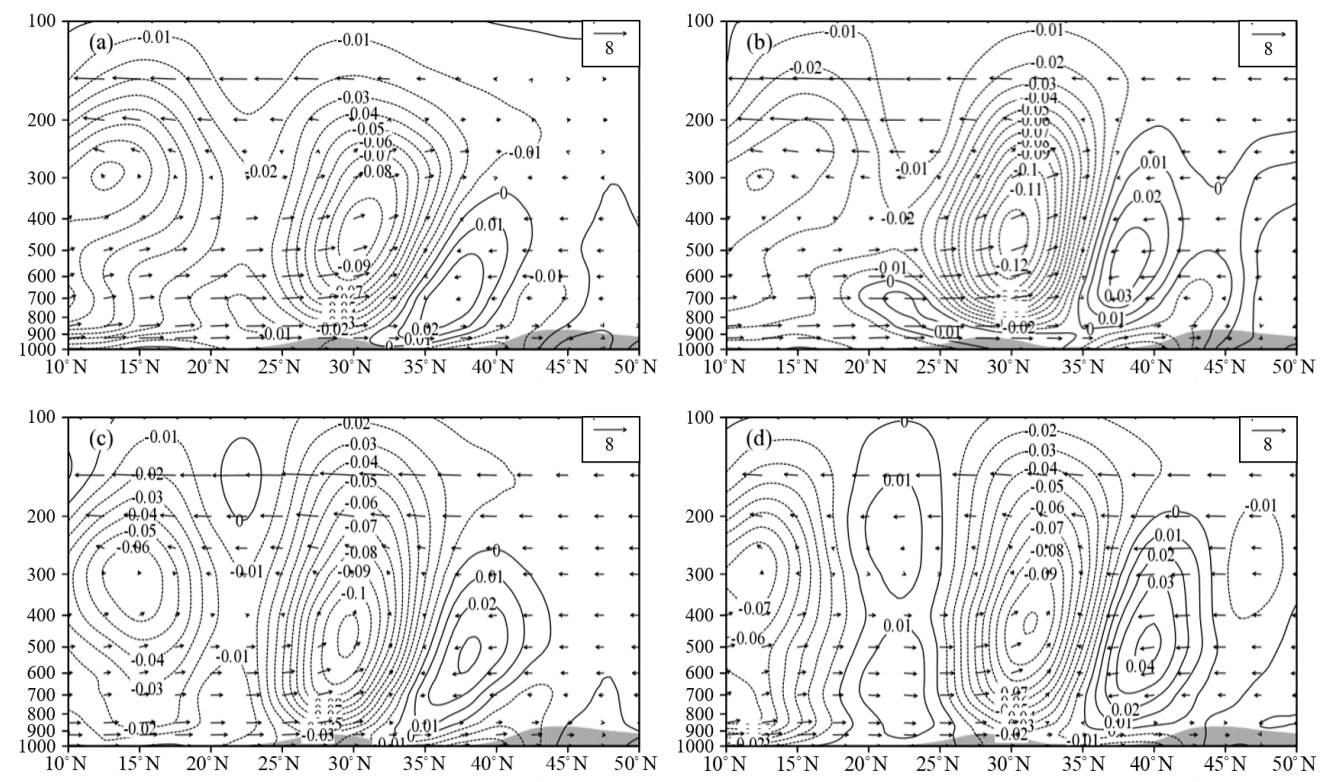

Figure 8. Profile along the mean $116 \sim 122^{\circ} \mathrm{E}$ of vertical velocity field (solid line, unit: $\mathrm{m} \cdot \mathrm{s}^{-1}$ ) and wind field (vector, unit: $\mathrm{s}^{-1}$, the vertical velocity is magnified 10 times); the shaded areas denote the topography of years of early Meiyu arrival in the 1990s (a), late Meiyu arrival in the 1990s (b), early Meiyu arrival in the 2010s (c), and late Meiyu arrival in the 2010s (d).

\section{Conclusions}

This work presents the variation of Meiyu in Jiangsu Province in recent 30 years by comparing the characteristic cases of the 1990s and the 2010s. The main conclusions are as follows:

(1) Since the 1990s, the Meiyu in Jiangsu Province has been delayed, and there was no extremely early Meiyu year in the 2010s. In the 1990s, the precipitation intensity was stronger than that in the 2010s in Jiangsu Province, and the difference between the early and late Meiyu years was obvious. The 2010s had less rainfall, fewer numbers of rainstorm days, and similar precipitation characteristics between the years of the early and late Meiyu arrival.

(2) At the upper troposphere, the SAH and the upper-level jet have a major impact on Meiyu. The position of the SAH in the 2010s was far eastward in comparison with that in the 1990s, which was not conducive to precipitation in the Meiyu period in the YangtzeHuaihe region. For the early-arriving Meiyu of the 1990s, the effect of the subtropical westerly jet was one of the reasons for multiple rainfall processes, and the strong and northerly upper-level jet in June, which indicated a strong summer monsoon, induced an early Meiyu onset. In the 2010s, the position of the upper-level jet is west and the range is small, and the difference of the upper-level jet was not significant, so the precipitation was weak and similar.

(3) The WPSH and blocking situation in the middle troposphere are important factors affecting Meiyu. The ridgeline of the WPSH in the years of the early Meiyu during the 1990s completed its northward jump at the beginning of June, causing an earlier Meiyu onset. In the late 1990s, the WPSH ridgeline remaining in low latitudes for a long term was the reason for a late Meiyu onset. Although in the 2010s, a large range of WPSH appeared early for the Meiyu of early arrival, the ridgeline did not jump north earlier, so there was no extremely early Meiyu onset. During the 2010s, the WPSH in the late-arriving Meiyu years jumped to the north earlier but retreated to the south soon, and the time it finally completed the north lifting was late, so the Meiyu started late. In addition, the east-blocking high in the early-arriving Meiyu years in the 1990s was more conducive to the southward movement of cold air that strengthened the Meiyu precipitation, while the atypical blocking situation in the years of the late Meiyu arrival of the 1990s and the 2010s hindered the occurrence of Meiyu precipitation. 
(4) In the 1990s, there was a stronger water vapor convergence in the Yangtze-Huaihe region, which provided the water vapor condition for more precipitation. The water vapor transport sources are different in different decades, and the change of water vapor channels in the 1990s and the 2010s was also one of the reasons for the variation of precipitation characteristics. On the whole, water vapor transport from the three sources of the Indian Ocean, the South China Sea, and the Western Pacific was stronger in the 1990s than in the 2010s, and less water vapor transport in the 2010s reduced the precipitation in the Yangtze-Huaihe region. In addition, in the 2010s the vertical transportation of Jiangsu and its south side weakened, and there even existed a large subsidence area in the years of the late Meiyu arrival, which had a negative impact on precipitation.

Author Contributions: Supervision, L.W.; Writing—review \& editing, R.H. Both authors have read and agreed to the published version of the manuscript.

Funding: This research was jointly supported by the National Natural Science Foundations of China (41975085) and the National Key R\&D Program of China (2019YFC1510004).

Institutional Review Board Statement: Not applicable.

Informed Consent Statement: Not applicable.

Data Availability Statement: All data used in this study are available upon request.

Acknowledgments: The authors are grateful to the reviewers and the editor for valuable comments and suggestions.

Conflicts of Interest: The authors declare no conflict of interest.

\section{References}

1. Ye, D.; Huang, R. Progress, achievements and problems in the research on the causes and prediction of drought and flood in the Yangtze and yellow river basins in China. Prog. Geosci. 1991, 4, 24-29.

2. Huang, Q.; Wang, L.; He, J.; Guan, Z. Review of research on Meiyu in Jianghuai. Zhejiang Meteorol. 2010, 31, $2-7$.

3. Tao, S.; Zhu, W.; Zhao, W. On the interannual variation of Mei Yu. Atmos. Sci. 1988, 12, 13-21.

4. Yang, Z.; Wang, W.; He, L. Anomalous characteristics of tropical atmospheric circulation in rainy and rainy years. J. Trop. Meteorol. 1997, 1, 47-56.

5. Tao, S.; Xu, S. Circulation characteristics of persistent drought and flood in Jianghuai River Basin in summer. J. Meteorol. 1962, 1, 1-10.

6. Liu, Y.; Hong, J.; Liu, C.; Zhang, P. Meiyu flood in Huaihe River and seasonal advance anomaly of subtropical high in the Western Pacific. Atmos. Sci. 2013, 37, 439-450.

7. Zhu, Q.; Lin, J.; Shou, S.; Tang, D. Synoptic Principles, 4th ed.; Meteorological Publishing House: Beijing, China, 2007; pp. 354-358.

8. Nie, Y.; Zhou, J.; Gu, X.; Zhou, Y.; Du, X. Diagnosis and analysis of a case of heavy rainstorm in Southeast Guizhou in the western section of "6.18" Meiyu front. Rainstorm Disaster 2018, 37, 445-454.

9. Xu, H.; Liu, J.; Deng, J. Projections of East Asian summer monsoon change at global warming of 1.5 and $2{ }^{\circ} \mathrm{C}$. In Proceedings of the 35th Annual Meeting of China Meteorological Society S4 2018 National Symposium on Tropical and Marine MeteorologySymposium on Generation Mechanism and Prediction Technology of Tropical Extreme Weather and Climate Events, Hefei, China, 24 October 2018; China Meteorological Society: Beijing, China, 2018; p. 95.

10. Wu, C.; Liu, Y. Response of Meiyu in Jianghuai river basin to global warming. In Proceedings of the S6 East Asian Climate Multi Time Scale Variation Mechanism and Climate Prediction at the 34th Annual Meeting of China Meteorological Society, Zhengzhou, China, 26-29 September 2017; China Meteorological Society: Beijing, China, 2017; p. 373.

11. Jiang, W.; Gao, H. New characteristics and cause analysis of Meiyu in the middle and lower reaches of the Yangtze River in the 21st century. Meteorology 2013, 39, 1139-1144.

12. Jiang, W.; Lv, J.; Xiang, Y. Abnormal characteristics and prediction of Meiyu in Jiangsu Province in recent 10 years. In Proceedings of the Subtropical Monsoon and Climate Change Branch of the 27th Annual Meeting of China Meteorological Society, Beijing, China, 21 October 2010.

13. Gu, W.; Chen, L. Characteristics of ocean atmosphere and its impact on China's climate in summer 2018. Meteorology 2019, 45, 126-134.

14. Zhang, F.; He, L. Atmospheric circulation and weather analysis in June 2018. Meteorology 2018, 44, 1237-1244.

15. Li, J.; He, L. Atmospheric circulation and weather analysis in June 2017. Meteorology 2017, 43, 1160-1164.

16. Zheng, Z.; Wang, Y. Characteristics of atmospheric circulation in the northern hemisphere in summer 2017 and its impact on China's weather and climate. Meteorology 2018, 44, 199-205.

17. Cao, Y.; Zhang, T. Atmospheric circulation and weather analysis in June 2016. Meteorology 2016, 42, 1154-1160. 
18. Si, D.; Liu, Y.; Shao, X.; Wang, Y. Ocean and atmospheric circulation anomalies in 2015 and their impact on China's climate. Meteorology 2016, 42, 481-488.

19. Guan, Y.; He, L. Atmospheric circulation and weather analysis in June 2014. Meteorology 2014, 40, 1159-1164.

20. Wen, M.; Shi, X. Relationship between the West Pacific subtropical high activity and condensation latent heat heating in summer 1998. Plateau Meteorol. 2006, 25, 616-623.

21. Mason, R.B.; Anderson, C.E. The development and decay of the100mb summertime anticyclone over Southern Asia. Mon. Weather Rev. 1958, 91, 312.

22. Liu, M. Impact of South Asia high on Meiyu characteristics in Jiangsu during flood season. In Proceedings of the Climate Credit Conference of 2007 Annual Meeting of China Meteorological Society, Guangzhou, China, 23-25 November 2007; China Meteorological Society: Beijing, China, 2007; pp. 1340-1348.

23. Lu, M.; Zhu, F.; Huang, W. 100 hPa South Asia High eigenvector and its relationship with summer precipitation in China. Trop. Meteorol. 1987, 1, 42-49.

24. Liu, J.; Kuang, X.; Zhang, Y. Relationship between subtropical westerly jet and subtropical (South Asian) high in the upper troposphere. Meteorol. Sci. 2010, 30, 34-41.

25. Du, Y.; Zhang, Y.; Xie, Z. Influence of East-West morphological change of upper westerly jet on spatial distribution of precipitation in Meiyu period. J. Meteorol. 2008, 66, 566-576.

26. Li, C.; Han, G.; Liu, M.; Sun, H.; Zhou, L. Relationship between East Asian upper jet anomaly and Jianghuai Meiyu. Meteorol. Sci. 2015, 35, 176-182.

27. Zhou, Z. Jianghuai Meiyu; Meteorological Publishing House: Beijing, China, 1996; pp. 134-135.

28. Zhang, C.; Song, L.; Li, Y. Research progress of summer blocking process in East Asia. J. Meteorol. 2004, 1, $119-127$.

29. Jiang, Z.; Ren, W.; Liu, Z.; Yang, H. Analysis of water vapor transport characteristics of Jianghuai Meiyu based on Lagrange method. J. Meteorol. 2013, 71, 295-304.

30. Wang, Z.; Gao, Q.; Hu, B.; Sun, Y. Study on water vapor transport characteristics during Meiyu period in Jianghuai region in recent 50 years. J. Atmos. Sci. 2017, 40, 48-60.

31. Guo, Y.; Wang, J.; Li, C.; Long, L. Effect of frontogenesis on Rainstorm in Hubei during the plum flood season in 2011. Meteorology 2014, 40, 86-93.

32. Yang, S.; Lu, Y.; Yu, C. Mesoscale convective system and low-level wind field impact analysis of a Meiyu Front Rainstorm. Meteorology 2017, 43, 21-33. 